\title{
Physiological insights of recent clinical diagnostic and therapeutic technologies for cardiovascular diseases
}

\author{
Kenji Shigemi $^{1} \cdot$ Soichiro Fuke $^{2} \cdot$ Dai Une $^{3} \cdot$ Keita Saku $^{4} \cdot$ Shuji Shimizu $^{5}$. \\ Toru Kawada $^{5} \cdot$ Toshiaki Shishido $^{6} \cdot$ Kenji Sunagawa $^{4} \cdot$ Masaru Sugimachi $^{5}$
}

Received: 21 March 2017/Accepted: 22 June 2017/Published online: 5 July 2017

(c) The Physiological Society of Japan and Springer Japan KK 2017

\begin{abstract}
Diagnostic and therapeutic methods for cardiovascular diseases continue to be developed in the 21 st century. Clinicians should consider the physiological characteristics of the cardiovascular system to ensure successful diagnosis and treatment. In this review, we focus on the roles of cardiovascular physiology in recent diagnostic and therapeutic technologies for cardiovascular diseases. In the first section, we discuss how to evaluate and utilize left ventricular arterial coupling in the clinical settings. In the second section, we review unique characteristics of pulmonary circulation in the diagnosis and treatment of pulmonary hypertension. In the third section, we discuss physiological and anatomical factors associated with graft patency after coronary artery bypass grafting. In the last
\end{abstract}

Kenji Shigemi, Soichiro Fuke, Dai Une and Keita Saku contributed equally to this paper.

Shuji Shimizu

shujismz@ri.ncvc.go.jp

1 Department of Anesthesiology and Reanimatology, University of Fukui Faculty of Medical Sciences, Fukui, Japan

2 Department of Cardiology, Japanese Red Cross Okayama Hospital, Okayama, Japan

3 Division of Cardiovascular Surgery, Yamato Seiwa Hospital, Yamato, Kanagawa, Japan

4 Department of Therapeutic Regulation of Cardiovascular Homeostasis, Center for Disruptive Cardiovascular Medicine, Kyushu University, Fukuoka, Japan

5 Department of Cardiovascular Dynamics, National Cerebral and Cardiovascular Center, 5-7-1 Fujishiro-dai, Suita, Osaka 565-8565, Japan

6 Department of Research Promotion, National Cerebral and Cardiovascular Center, Suita, Osaka, Japan section, we discuss the usefulness of mechanical ventricular unloading after acute myocardial infarction. Clinical development of diagnostic methods and therapies for cardiovascular diseases should be based on physiological insights of the cardiovascular system.

Keywords Cardiovascular physiology - Left ventricular arterial coupling · Pulmonary circulation · Coronary artery bypass grafting $\cdot$ Left ventricular assist device

\section{Introduction}

Diagnostic and therapeutic methods for cardiovascular diseases have been developed at a rapid pace in the past several decades. Various new drugs and devices for cardiovascular diseases have been introduced in the $21 \mathrm{st}$ century. Noninvasive diagnostic methods, such as cardioankle vascular index (CAVI), are one of the recent topics in the field of clinical diagnoses of cardiovascular diseases. In the near future, these non-invasive diagnostic methods may replace invasive methods for evaluating physiological characteristics of the cardiovascular system. Furthermore, upcoming drugs and devices will significantly improve clinical outcome in patients with severe cardiovascular dysfunction.

Although clinicians should take into consideration the physiological characteristics of the cardiovascular system for successful cardiovascular diagnosis and therapy, accurate evaluation of these characteristics such as ventricular end-systolic elastance, arterial elastance and impedance, and shear stress of vessels is sometimes difficult in the clinical setting because accurate measurements of physiological values, i.e., pressure, flow, and volume, require invasive methods such as catheterization. 
Upcoming noninvasive diagnostic devices will be helpful in evaluating these physiological characteristics in the near future. Physiological characteristics evaluated using such devices may be good predictors of cardiovascular prognosis. Furthermore, cardiovascular therapies based on cardiovascular physiology, such as mechanical ventricular unloading to reduce systolic pressure-volume area (PVA), may further improve therapeutic outcomes in patients with severe cardiovascular dysfunction.

In this review, we focus on the roles of cardiovascular physiology in recent diagnostic and therapeutic technologies for cardiovascular diseases. Four topics are selected from the viewpoint of medical specialists, an anesthesiologist, cardiologists, and a cardiovascular surgeon, who work in the forefront of clinical medicine: (1) left ventricle and systemic circulation, (2) right ventricle and pulmonary circulation, (3) coronary circulation, and (4) mechanical ventricular assist device (VAD). In the first section, we discuss how to evaluate left ventricular arterial coupling in the clinical setting, and report the usefulness of noninvasive diagnostic methods for its evaluation. In the second section, we review unique physiological characteristics of right ventricle and pulmonary circulation for clinical diagnosis and treatment of pulmonary arterial hypertension. In the third section, we discuss physiological and anatomical factors that affect graft patency after coronary artery bypass grafting (CABG). In the last section, we discuss the usefulness of mechanical ventricular unloading using VAD for acute myocardial infarction from the viewpoint of ventricular energetics.

\section{Monitoring and clinical application of left ventricular arterial coupling (Ees/Ea)}

Estimation of ventricular arterial coupling (Ees/Ea) is clinically useful in general anesthesia and critical care, since cardiac performance such as cardiac output and ejection fraction depends on Ees/Ea, and the efficacy of energetic transfer from the heart to the artery is also related to Ees/Ea. In a previous study, the left ventricular time-varying elastance curve was approximated by two straight lines, and left ventricular end-diastolic pressure was assumed to be zero for estimating Ees/Ea using four noninvasive parameters: end-systolic arterial pressure (Pes), diastolic arterial pressure (Pd), preejection period (PEP), and ejection time (ET) [1]. Pes was substituted by mean arterial pressure $(\mathrm{Pm})$ to apply this estimation method to clinical monitoring. Although estimated values varied widely among individuals, the accuracy of Ees/Ea was high enough for clinical use, as discussed below.

\section{Basics of Ees and Ea}

A loop showing the pressure-volume relationship can be drawn using simultaneously measured left ventricular pressure and volume (Fig. 1). The slope of the line connecting the upper left of this loop and the volume-axis intercept $\left(V_{0}\right)$ of the end-systolic pressure-volume relationship (ESPVR) is the end-systolic elastance (Ees), which expresses left ventricular systolic performance. The slope of the line connecting the upper left of the loop and the lower right corner (left ventricular end-diastolic volume; Ved) is the effective arterial elastance (Ea), which expresses ventricular afterload. The pressure at the intersection of these two lines is the counterbalance pressure of artery and ventricle (end-systolic pressure, Pes). As shown in Fig. 1, Ees and Ea are defined as follows:

Ees $=$ Pes $/\left(\right.$ Ves $\left.-V_{0}\right)$

$\mathrm{Ea}=$ Pes $/($ Ved - Ves $)=$ Pes $/$ SV

where Ves is end-systolic ventricular volume, and SV is stroke volume.

\section{Physiological and clinical significance of Ees/Ea}

Ees/Ea shows the efficiency of left ventricular contraction that pumps blood through the arteries. The heart usually contracts most efficiently when the carotid sinus baroreflex maintains a constant Ees/Ea against physiological disturbances [2]. Therefore, any change in Ees/Ea may predict insufficiency of the cardiovascular control system.

Clinically, Ees/Ea can change even when arterial pressure is maintained, such as in states of septic shock and compensatory elevated peripheral vascular resistance when heart failure is exacerbated for a short time. Monitoring of

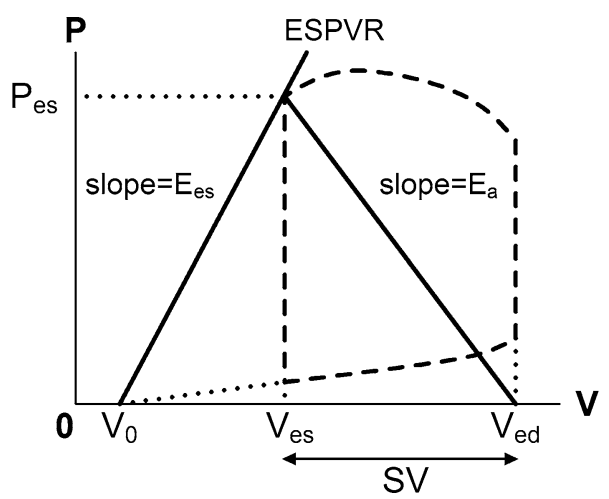

Fig. 1 Ventricular pressure-volume relationship. ESPVR end-systolic pressure-volume relationship, Pes end-systolic arterial pressure, Ves end-systolic left ventricular volume, Ved end-diastolic left ventricular volume, $V_{O}$ the volume-axis intercept of ESPVR, Ees end-systolic left ventricular elastance, $E a$ effective arterial elastance, $S V$ stroke volume 
Ees/Ea may predict changes in arterial pressure before they occur.

\section{Problems of Ees/Ea monitoring in clinical settings}

The Ees (or ESPVR) has been determined by drawing multiple pressure-volume loops and a tangent line on the upper left of the multiple loops, when ventricular preload is decreased by inflating a balloon placed in the inferior vena cava with simultaneous high-fidelity measurements of left ventricular pressure and volume. This procedure is very invasive and not practical in clinical settings. To obtain Ees more easily, many less invasive single-beat estimation methods have been reported [3, 4], all of which require approximation and are not suitable for online processing.

\section{Single-beat estimation of Ees/Ea without volume measurement}

To avoid high-fidelity volume measurement, Shishido et al. [5] developed a framework of single-beat Ees estimation by approximating the time-varying elastance curve by two linear functions in the isovolumic contraction phase and ejection phase. As shown in Fig. 2a, Ees can be expressed as

Ees $=\mathrm{Ead}+(\mathrm{Ead}-\mathrm{Eed}) \cdot k \cdot \mathrm{ET} / \mathrm{PEP}$

where Ead, Eed, and $k$ denote elastance at the end of the isovolumic contraction phase, end-diastolic elastance, and ratio of the slope in ejection phase to that in isovolumic contraction phase, respectively. As shown in Fig. 2b, the pressure at the end of isovolumic contraction phase (Pad), end-diastolic pressure (Ped), and peak isovolumic pressure (Pmax) can be expressed using Ead, Eed, and Ees, respectively.

$$
\begin{aligned}
\text { Pad } & =\text { Ead } \cdot\left(\text { Ved }-V_{0}\right) \\
\text { Ped } & =\text { Eed } \cdot\left(\text { Ved }-V_{0}\right) \\
\text { Pmax } & =\text { Ees } \cdot\left(\text { Ved }-V_{0}\right)
\end{aligned}
$$

Multiplying Eq. (3) on both sides by $\left(\right.$ Ved- $\left.\mathrm{V}_{0}\right)$ yields:

Pmax $=\mathrm{Pad}+(\mathrm{Pad}-\mathrm{Ped}) \cdot k \cdot \mathrm{ET} / \mathrm{PEP}$

Ees can be estimated using Pmax, Pes, and stroke volume (SV) as shown in Fig. 2b:

Ees $=(\operatorname{Pmax}-\mathrm{Pes}) / \mathrm{SV}$

This framework requires no high-fidelity volume measurement. Ees can be obtained from SV and left ventricular pressure measurements. Hence, this framework allows calculation of Ees/Ea without volume measurements.

Using this framework, Ees/Ea can be expressed as:

Ees $/ \mathrm{Ea}=($ Pmax - Pes $) /$ Pes

Hayashi et al. [1] simplified this method for further clinical application. When Ped $=0$, Eq. (5) will be simplified as:

$\mathrm{Pmax}=\mathrm{Pad}+\mathrm{Pad} \cdot k \cdot \mathrm{ET} / \mathrm{PEP}$

Substituting Pmax in Eq. (7) with Eq. (5') yields:

$\mathrm{Ees} / \mathrm{Ea}=\mathrm{Pad} / \mathrm{Pes} \times(1+\mathrm{k} \cdot \mathrm{ET} / \mathrm{PEP})-1$

Since Pad can be replaced by arterial diastolic pressure (Pd), Eq. (8) is expressed as:

$\mathrm{Ees} / \mathrm{Ea}=\mathrm{Pd} / \mathrm{Pes} \times(1+k \cdot \mathrm{ET} / \mathrm{PEP})-1$

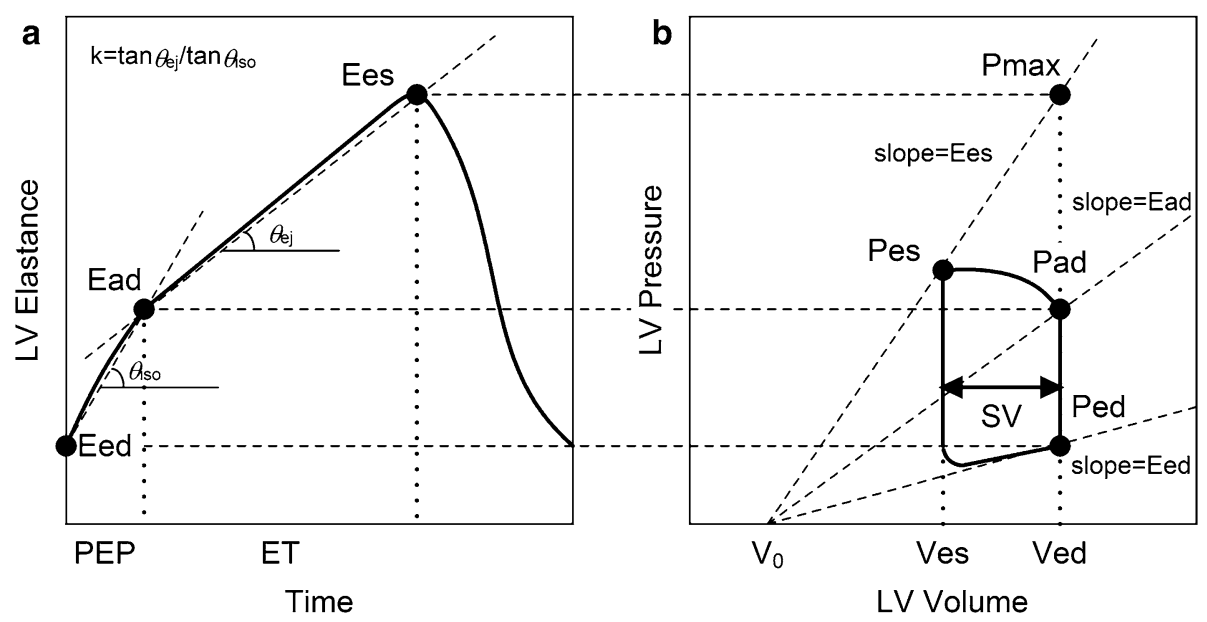

Fig. 2 Schematic representation of a framework of single-beat endsystolic left ventricular elastance (Ees) estimation by approximating the time-varying elastance curve as two linear functions. a Timevarying elastance curve (solid line) and two linear approximations (dashed line). b Estimated end-systolic pressure-volume loop (solid line). $L V$ left ventricle, Ead elastance at the end of isovolumic contraction phase, Eed end-diastolic elastance, $P E P$ pre-ejection period, ET ejection time, $\theta i s o$ and $\theta e j$ angles of approximated lines of isovolumic contraction phase and ejection phase, respectively, Pmax peak isovolumic pressure, $\mathrm{Pad}$ pressure at the end of isovolumic contraction phase, $P e d$ end-diastolic pressure 
Fig. 3 Upper panels, scatter plot (a) and Bland-Altman plot (b) to analyze the correlation between ventricular arterial coupling (Ees/Ea) obtained by the original method using endsystolic arterial pressure (Pes), expressed as Ees/Ea, and Ees/Ea approximated using mean arterial pressure $(\mathrm{Pm})$, expressed as $(\mathrm{Ees} / \mathrm{Ea})^{\prime}$. Lower panels, scatter plot (c) and Bland-Altman plot (d) to analyze the correlation between ventricular arterial coupling (Ees/Ea) obtained using endsystolic arterial pressure (Pes), expressed as Ees/Ea, and the adjusted values of (Ees/Ea)' [approximated using mean arterial pressure $(\mathrm{Pm})]$ expressed as $\operatorname{adj}(\mathrm{Ees} / \mathrm{Ea})^{\prime}$
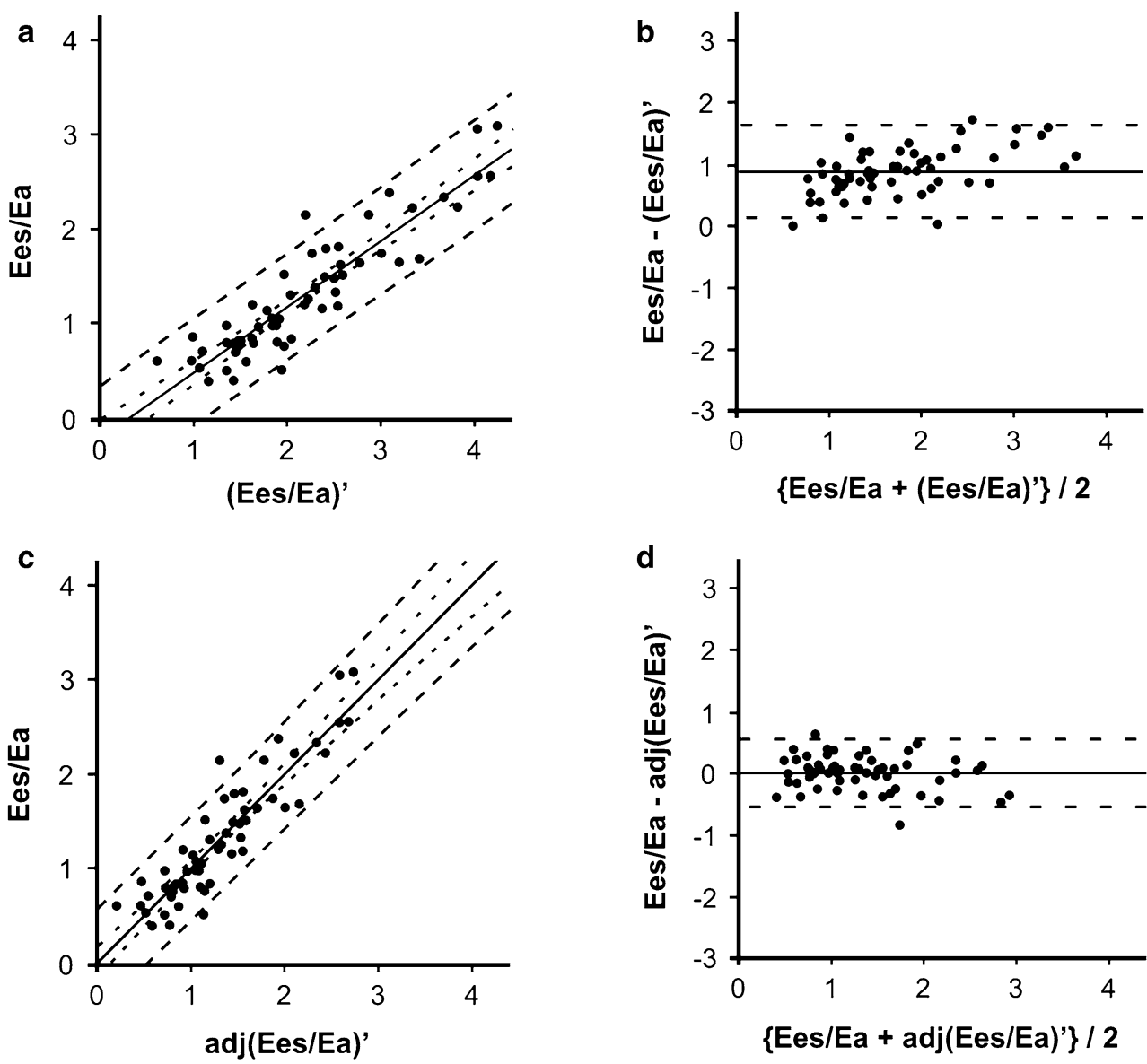

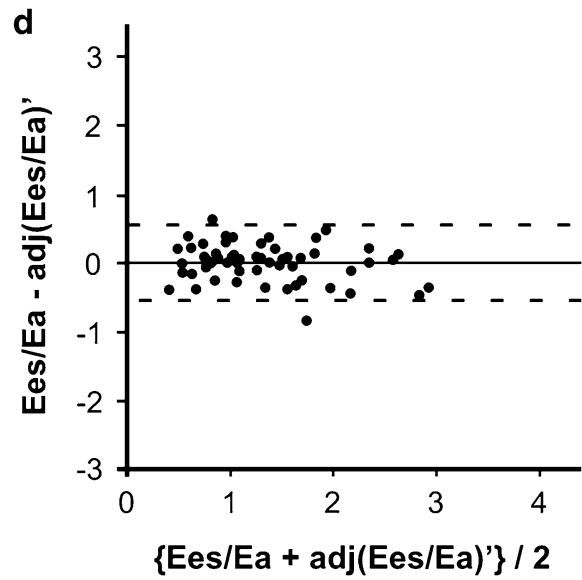

The value of $k$ has been reported to correlate with Ees/ Ea in animal study [1]. Using Ees/Ea, the value of $k$ is approximated as:

$k=0.53 \times(\mathrm{Ees} / \mathrm{Ea})^{0.51}$

Without volume parameters, Ees/Ea can be described using four parameters: Pes, Pd, PEP, and ET. However, since this method still requires left ventricular pressure measurement, it can only be used in patients undergoing cardiac catheterization.

\section{Approximation to obtain Ees/Ea only from arterial pressure waveform}

Because left ventricular pressure measurement is far more invasive than hemodynamic monitoring used in routine practice, mean arterial pressure $(\mathrm{Pm})$ may be used as a surrogate of Pes [6]. Ees/Ea obtained using Pm is shown in the following formula as (Ees/Ea)'.

$$
\begin{aligned}
& (\mathrm{Ees} / \mathrm{Ea})^{\prime}=\mathrm{Pd} / \mathrm{Pm} \times(1+k \cdot \mathrm{ET} / \mathrm{PEP})-1 \\
& k=0.53 \times\left[(\mathrm{Ees} / \mathrm{Ea})^{\prime}\right]^{0.51}
\end{aligned}
$$

A vascular screening system (VaSera VS-1000 or 1500, Fukuda Denshi, Tokyo, Japan) that performs limb lead electrocardiogram, phonocardiogram, and blood pressure measurements in bilateral upper and lower extremities was used to test this approximation. This system calculates arterial stiffness from the heart to the ankles (cardio-ankle vascular index: CAVI) and stenosis or occlusion of the arteries in lower limbs (ankle brachial pressure index: ABI). This system outputs the arterial pressure waveform, systolic blood pressure (Ps), Pm, Pd, PEP, and ET, in addition to electrocardiogram and phonocardiogram, on standard report paper. Using this device, the height of the arterial pressure waveform (h1) and the height of the arterial notch (h2) were measured manually, and Pes was obtained from pulse pressure and Pd using Eq. (11) as shown below. The values obtained using Pes, expressed as Ees/Ea, and the values obtained using $\mathrm{Pm}$, expressed as $(\mathrm{Ees} / \mathrm{Ea})^{\prime}$ were compared in 101 patients at University of Fukui Hospital [7], and the correlation is shown in Fig. 3, upper panels. Linear regression was performed for adjustment of (Ees/Ea) $)^{\prime}$ obtained using Pm, and adjusted Ees/Ea was calculated by Eq. (12).

Pes $=(\mathrm{Ps}-\mathrm{Pd}) \times \mathrm{h} 2 / \mathrm{h} 1+\mathrm{Pd}$

$\mathrm{Ees} / \mathrm{Ea}=0.70 \times(\mathrm{Ees} / \mathrm{Ea})^{\prime}-0.22$ 
Pm and other parameters measured were substituted in the simultaneous equations of Eqs. $\left(9^{\prime}\right),\left(10^{\prime}\right)$, and (12), and the results were expressed as $\operatorname{adj}(\mathrm{Ees} / \mathrm{Ea})^{\prime}$. Pes and other parameters measured were substituted in the simultaneous equations of Eqs. (9) and (10), and the results were expressed as Ees/Ea. A good correlation between Ees/Ea and adj(Ees/ $\mathrm{Ea})^{\prime}$ was obtained as shown in Fig. 3, lower panels.

\section{Measurement using CAVI device and standard values of Ees/Ea}

To obtain the normal range of Ees/Ea, CAVI were measured using a vascular screening system from 2675 men and 2287 women who underwent health checkup at Fukuiken Saiseikai Hospital Checkup Center. At the same time, Ees/Ea was calculated using Pm, Pd, PEP, and ET, by Eqs. $\left(9^{\prime}\right),\left(10^{\prime}\right)$, and (12) (unpublished data).

The CAVI obtained from the subjects did not differ significantly from the distribution of normal values given in the instruction manuals of the instruments, indicating that the subjects were a healthy group. Although CAVI increases with aging, Ees/Ea is constant for all ages (Fig. 4), with an overall mean value and standard deviation of $1.2 \pm 0.6$.

Although ventricular contractility is influenced by various factors, such as heart rate and ventricular mass, Ees/Ea is a relatively stable index of ventricular performance. Heart rate affects ventricular contractility including Ees because of the positive force-frequency relationship [8]. Since Ea changes parallel to Ees when heart rate changes, the influence of heart rate on Ees/Ea may be relatively smaller than that on Ees or Ea [9]. There is a linear relationship between Ees and body mass [9]. On the other hand, Ees/Ea has been reported to be preserved

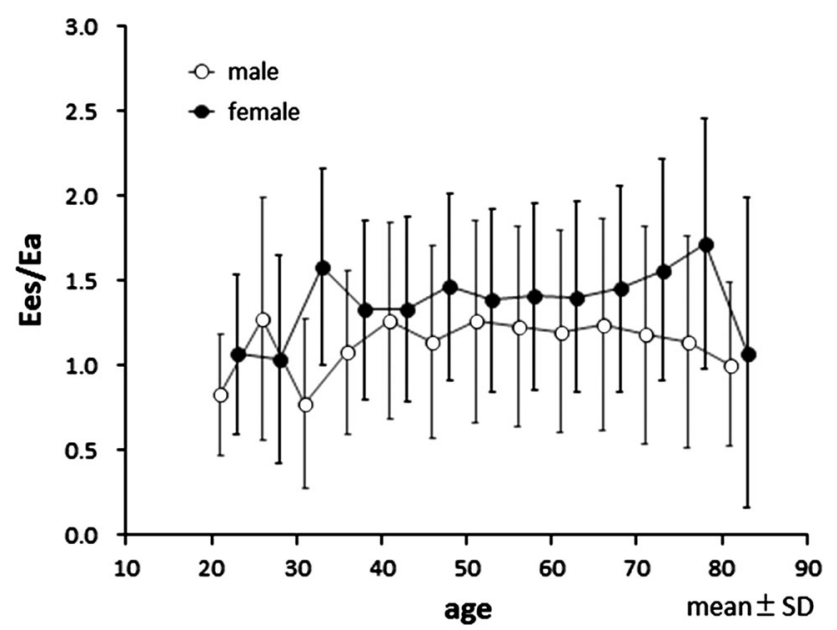

Fig. 4 Age distribution of ventricular arterial coupling (Ees/Ea) in males (open circles) and females (closed circles). The overall mean value and standard deviation (SD) is $1.2 \pm 0.6$ independent of heart size because the Windkessel parameters (characteristic impedance, peripheral resistance and total arterial compliance) also change according to the body mass [10]. Therefore, a monitoring of Ees/Ea will be more beneficial than that of Ees or Ea alone because the gender difference is relatively small.

\section{Limitations}

Several assumptions are made when estimating Ees/Ea with the four parameters; Pm, Pd, PEP, and ET, and several points should be kept in mind when using this estimation.

First, we assume zero Ped and use Pm as a surrogate of Pes in this estimation. Therefore, there is a possibility that Ees/Ea is overestimated when Ped is high. Furthermore, Ees/Ea will be miss-estimated when Pes is considerably higher than Pm. In these situations, several corrections of the four parameters are necessary. Although the absolute value of Ees/Ea obtained using this estimation is not identical to the true Ees/Ea measured by the conventional method by drawing left ventricular pressure-volume loops, continuous monitoring of intra-individual changes in Ees/ Ea may be beneficial in general anesthesia and critical care.

Second, estimated values vary greatly. There may be errors in the measurements of the four parameters. Since their products and quotients are calculated, the errors will be amplified. However, the normal ranges obtained in this study from a large study population should have high reliability. Furthermore, variability in these values for individual estimations can be lowered by creating a consecutive approximating system with electrocardiographic, phonocardiographic, and arterial waveform measurements. Calculating mean values from consecutive data points will reduce the variability.

\section{Summary}

Ees/Ea can be monitored continuously using four parameters (Pm, Pd, PEP, and ET) that can be measured less invasively from arterial pressure waveform. The mean \pm standard deviation of Ees/Ea was $1.2 \pm 0.6$ for all ages. Continuous monitoring of Ees/Ea is useful in general anesthesia and critical care.

\section{Unique physiological characteristics of pulmonary circulation}

Pulmonary circulation has some unique features different from those of systemic circulation, leading to different appearances of pressure and flow waveforms in the pulmonary artery from those in systemic arteries. Several selective vasodilators of pulmonary vessels, such as 

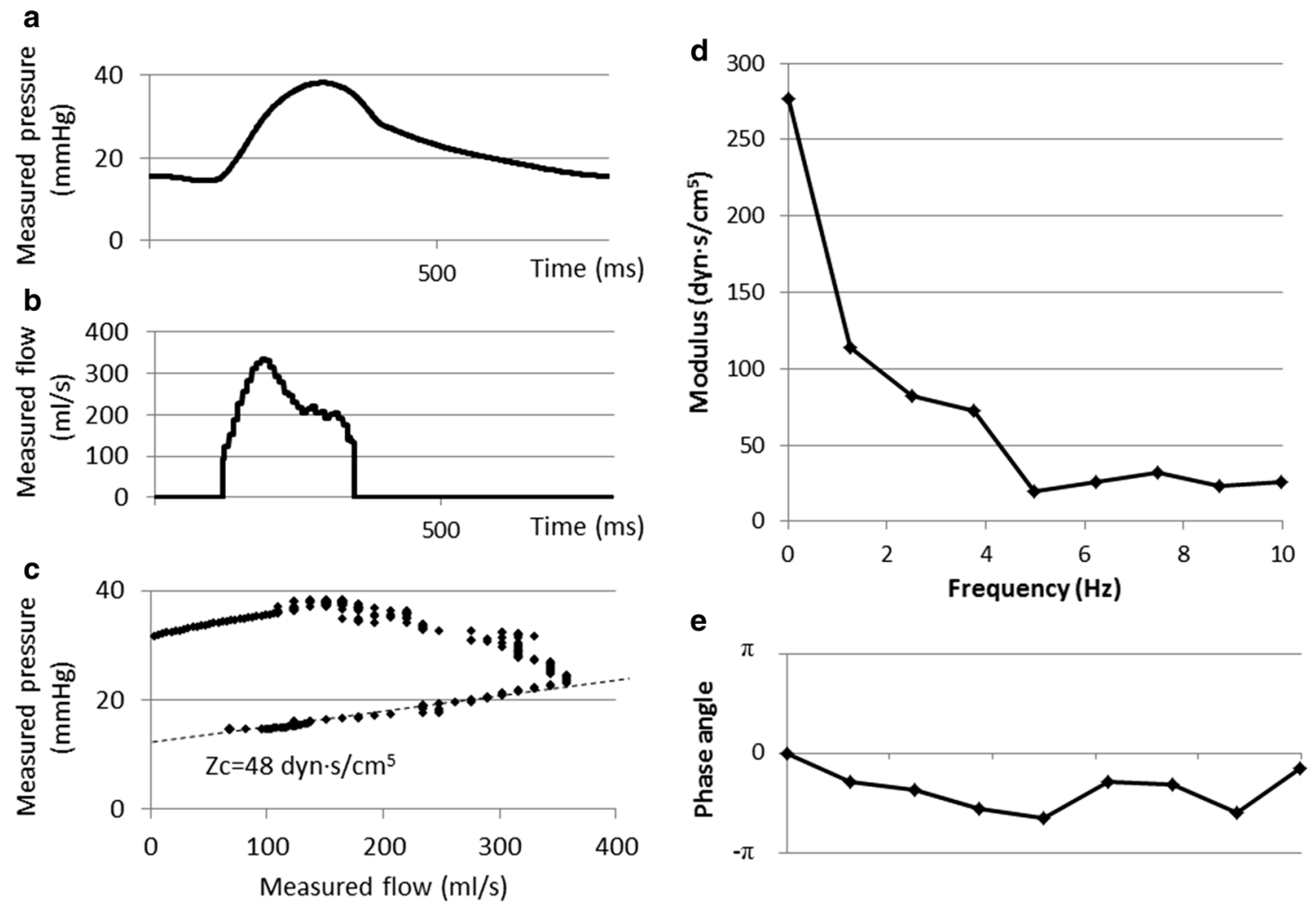

Fig. 5 Computation of pulmonary input impedance. a, b Pressure and flow waveforms, respectively, recorded simultaneously. c Characteristic impedance $(\mathrm{Zc})$ obtained from the instantaneous pulmonary

prostaglandin $I_{2}$ and sildenafil, have been used to treat pulmonary hypertension in the last two decades. These medications dramatically change the hydraulic nature of pulmonary vessels. To use these drugs properly, clinicians need to have physiological knowledge about the functions of pulmonary vessels and the right ventricle, and their interaction. In this section, we explain the hydraulic nature of the pulmonary circulation, right ventricular contractility, and interaction of the right ventricle and pulmonary vessels (Ees/ $\mathrm{Ea}$ ), and discuss the methods to quantify these features.

\section{Unique features of pulmonary circulation}

The lung is the only organ that receives the total blood volume ejected by the right ventricle. The SV of the right ventricle is equivalent to that of the left ventricle in a normal heart without shunt diseases. The absolute pressure and the amplitude of pulse pressure are smaller in the pulmonary circulation than in the systemic circulation, although the size of the arterial inlet (the main pulmonary trunk and the aorta) and volumetric flow are almost equivalent. This phenomenon is a result of lower resistive component against steady flow, lower impedance against oscillatory flow, and higher vascular distensibility in the pulmonary circulation than in the systemic circulation. The resistive component

pressure-flow plot (time domain manner) [13]. d, e Modulus and phase angle of the pulmonary input impedance computed from decomposed Fourier transform of pressure and flow, respectively

and impedance can be calculated quantitatively by computing the input impedance of the pulmonary artery. The distensibility of pulmonary vessels can be evaluated from the compliance or the pressure-flow relationship.

\section{Pulmonary impedance}

Pulmonary vascular resistance (PVR) is a hemodynamic index derived from the quotient of trans-pulmonary pressure over cardiac output. The PVR represents simple hydraulic vascular resistance in steady blood flow. However, because the blood flow is pulsatile, pulmonary input impedance is used to represent the pulsatile hydraulic vascular nature. The input impedance is computed by simultaneous recording of pressure $[p(t)]$ (Fig. 5a) and flow $[q(t)]$ (Fig. 5b). Harmonic decomposes of pressure $[P(f)]$ and flow $[Q(f)]$ are obtained by Fourier transform $[F(x)]$.

$P(f)=F(p(t)-\mathrm{PAOP})$

$Q(f)=F(q(t))$

where PAOP is pulmonary artery occlusion pressure. The input impedance $[Z(f)]$ is calculated as:

$Z(f)=P(f) / Q(f)$ 
Table 1 Pulmonary input impedance in normal adult subjects and patients with pulmonary hypertension

\begin{tabular}{|c|c|c|c|c|c|c|c|}
\hline Authors & Year & $n$ & Diagnosis & PAP (mmHg) & PVR (dyn $\left.\cdot s / \mathrm{cm}^{5}\right)$ & $\mathrm{Z} 1\left(\mathrm{dyn} \cdot \mathrm{s} / \mathrm{cm}^{5}\right)$ & $\mathrm{Zc}\left(\right.$ dyn $\left.\cdot \mathrm{s} / \mathrm{cm}^{5}\right)$ \\
\hline \multicolumn{8}{|l|}{ Normal subjects } \\
\hline Milnor et al. [17] & 1969 & 3 & & 13.9 & 97 & & 23 \\
\hline Murgo et al. [18] & 1984 & 10 & & 14.9 & 79 & & 20 \\
\hline Chen et al. [19] & 1990 & 8 & & 19.3 & 175 & 49 & 34 \\
\hline Slife et al. [20] & 1990 & 8 & & 13.3 & 73 & & 22 \\
\hline Laskey et al. [21] & 1993 & 10 & & 14 & 73 & 38 & 22 \\
\hline Noda et al. [22] & 2006 & 12 & & 15 & 241 & 46 & 37 \\
\hline \multicolumn{8}{|c|}{ Pulmonary hypertension } \\
\hline Milnor et al. [17] & 1969 & 7 & MS & 40.2 & 340 & & 46 \\
\hline Yin et al. [23] & 1983 & 7 & $\mathrm{HF}$ & 37.6 & 457 & & 49 \\
\hline Chen et al. [19] & 1990 & 8 & COPD & 35.4 & 469 & 169 & 59 \\
\hline Laskey et al. [21] & 1993 & 8 & PPH & 50 & 880 & 385 & 55 \\
\hline Huez et al. [24] & 2004 & 22 & PAH & 63 & 1282 & 289 & 124 \\
\hline
\end{tabular}

$C O P D$ chronic obstructive pulmonary disease, $H F$ heart failure, $M S$ mitral stenosis, $P A H$ pulmonary arterial hypertension, $P A P$ mean pulmonary artery pressure, $P P H$ primary pulmonary hypertension, $P V R$ pulmonary vascular resistance, $Z 1$ input impedance at 1 st harmonic, $Z c$ characteristic impedance

Since each input impedance is a complex number, information regarding the magnitude (Fig. 5d) and phase (Fig. 5e) can be obtained. An augmentation of the reflected wave at a given frequency demonstrates a delay of phase [11].

Caro and McDonald [12] reported an important experimental study in 1961. They measured pulmonary impedance in isolated perfused lungs of rabbits, in which oscillated flow was generated by a sinusoidal pump that imposed a range of frequencies on steady flow. In this study, the modulus of pulmonary input impedance was measured at various frequencies. After their report, several studies examined pulmonary input impedance in dogs using harmonic analysis based on Fourier transform of the pressure and flow waveforms [13, 14]. The input impedance spectrum consists of impedance at $0-\mathrm{Hz}$ frequency as PVR, characteristic impedance $(\mathrm{Zc})$ at high frequencies usually measured between 4 and $8 \mathrm{~Hz}$ as large vessel stiffness, and an impedance curve at each frequency. Zc can also be measured in a time-domain manner (Fig. 5c) [15]. Because each input impedance is a complex number, the input impedance spectrum contains information regarding the phase angle. An augmentation of reflected wave at each frequency denotes a delay of phase angle in the input impedance spectrum [11]. In humans, pulmonary input impedance can be measured using a catheter with tip-mounted flow probe and pressure transducer [16]. Zc was reported to be $20-37 \mathrm{dyn} \cdot \mathrm{s} / \mathrm{cm}^{5}$ in normal adults [17-22], and 46-124 dyn $\cdot \mathrm{s} / \mathrm{cm}^{5}$ in patients with pulmonary hypertension $[17,19,21,23,24]$ (Table 1). Several studies also report measurement of pulmonary input impedance in clinical settings using pressure recorded by fluid-filled catheter systems and flow velocity simultaneously recorded by Doppler echocardiography [24, 25]. However, because signal delay and nonlinear response caused by damping of the fluid-filled system [26] are not considered in these studies, the modulus or phase angles measured by such methods may not be accurate.

\section{Distensibility of pulmonary vessels}

The simplest index of distensibility of the pulmonary vessels is the compliance $C$ defined as SV divided by pulse pressure: [27]

$C=\mathrm{SV} /(\mathrm{Ps}-\mathrm{Pd})$

where Ps and Pd are systolic and diastolic pressures, respectively.

This index is comparable to the capacitance of the twoelement Windkessel model, a simulator of the whole arterial tree. A decrease in pulmonary compliance is reported as an independent predictor of poor prognosis in patients with idiopathic pulmonary hypertension [28]. However, because this index may be influenced by other parameters such as arterial stiffness and peripheral resistance, the time constant of pulmonary artery pressure [29] may be a more feasible index of distensibility. Blockade of vascular inflow by valvular closure results in an exponential pressure fall induced by the flow from the capacitance to the resistive component. The time constant of the pulmonary arterial system is defined as the time interval required for pulmonary arterial pressure to fall from baseline value at time zero to $1 / e$ of the value, where $e$ is 
Napier's number. Although the time constant has been reported as constant in individuals [29], it may become shorter with decreased pulmonary vascular bed in patients with pulmonary hypertension $[30,31]$.

\section{Pulmonary pressure-flow relationship}

To prevent elevation in pulmonary arterial pressure, pulmonary vessels have autoregulatory systems such as passive distension, recruitment [32], and vascular waterfall [33] against increased pulmonary flow. The pressureflow relationship may be useful to evaluate the autoregulatory function. A regression curve of pulmonary driving pressure versus pulmonary blood flow reflects the whole pulmonary reaction against increased flow [34]. Because pulmonary arterial pressure is dependent on flow, comparison between PVR should be interpreted with caution especially in the lower range of cardiac output [35]. If pulmonary hypertension exists, this regression curve will become steeper, reflecting impaired pulmonary vascular autoregulation against increased flow (Fig. 6). The normal range of the slope of mean pulmonary arterial pressure versus cardiac output is between 0.5 and $2.5 \mathrm{mmHg} \cdot \mathrm{min} / \mathrm{l}$ [36]. However, because pulmonary arterial pressure is elevated partly as a result of elevated left atrial pressure in response to increased pulmonary blood flow or elevated left ventricular end-diastolic pressure during exercise, this index may not directly reflect pulmonary vascular autoregulation.

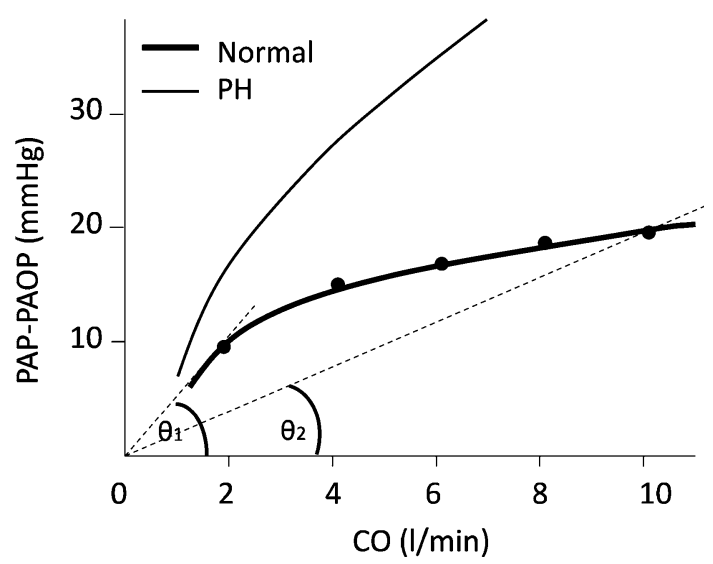

Fig. 6 The pressure-flow relationship of the pulmonary artery. In normal subjects, increase in trans-pulmonary pressure (PAP-PAOP) is suppressed in the high flow range. The angles of $\theta 1$ and $\theta 2$ indicate pulmonary artery resistance (PVR) at cardiac output of 2 and $10 \mathrm{l} /$ min, respectively. PVR varies with change in cardiac output even in the same subject [33]. In patients with pulmonary hypertension $(\mathrm{PH})$, this regression curve becomes steeper, reflecting impaired pulmonary vascular autoregulation against increased flow. $P A P$ mean pulmonary artery pressure, $P A O P$ pulmonary artery occlusion pressure

\section{Unique features of the right ventricle}

The morphology of the right ventricle is complex and completely different from that of the left ventricle. The cavity of the normal right ventricle has a trigonal pyramidal shape, and consists of three parts; the inlet segment, trabecular component, and outflow tract. The trabecular component consists of coarse trabeculated myocardium composed of thin-layered linear fibers extending to the apex, and intra-ventricular septal myocardium shared with the left ventricle. Right ventricular contraction is caused by longitudinal shortening of myocardial fibers in the right ventricular free wall. The SV of the right ventricle is equivalent to that of the left ventricle, but the stroke work is approximately $25 \%$ of that of the left ventricle because of low resistance of the pulmonary vasculature [37]. Any increase in right ventricular preload will cause chamber dilatation and tricuspid regurgitation, resulting in annular dilatation.

\section{Contractility of the right ventricle}

When the right ventricle is simulated by a time-varying elastance model [38-40], Ees represents ventricular contractility [41]. However, real-world evaluation of Ees requires the use of a conductance catheter. The conductance catheter technique is based on the assumption that the electrical field produced by the catheter is homogeneous and parallel to the longitudinal axis of the ventricle, and the current created by the excitation electrodes on the catheter is localized within the ventricular cavity [42]. To draw the pressure-volume loop of the right ventricle [43], preload interventions by vena cava occlusion or fluid overload are required. Because of the risk of hemodynamic collapse, this method may not be suitable for clinical application in patients with cardiovascular diseases such as pulmonary hypertension.

Another method to estimate Ees using left ventricular Pmax obtained from the pressure curve of a single ejecting contraction was proposed by Sunagawa and colleagues [44]. In brief, Pmax is estimated using an extrapolated sine curve fitted to the left ventricular pressure during the isovolumic period (Fig. 7a). Currently, this method is extended to the right ventricular pressure curve [45]. Ees of the right ventricle can be estimated by combining the right ventricular Pmax, Pes and SV (Fig. 7b).

Ees $=($ Pmax - Pes $) / S V$

The value of Ees was reported to be $1.1 \mathrm{mmHg} / \mathrm{ml}$ in normal subjects and $3.6 \mathrm{mmHg} / \mathrm{ml}$ in patients with pulmonary hypertension with mean pulmonary arterial pressure of $57 \mathrm{mmHg}$ [46]. However, there are several methodological limitations to evaluate Ees of the right 
Fig. 7 Computation of endsystolic elastance (Ees) of the right ventricle. a Peak isovolumic pressure (Pmax) from a given single contraction of the right ventricle is estimated from the extrapolated sine curve (dashed line) using the isovolumic pressure (shadowed periods) [42, 43]. b Ees is estimated by combining the Pmax, the right ventricular end-systolic pressure (Pes) and stroke volume (SV) [43]. The estimated pressure-volume loop of the right ventricle is drawn with a dashed line. Ea effective arterial elastance, $H M P$ hydromotive pressure, ICT isovolumic contraction time, $I R T$ isovolumic relaxation time

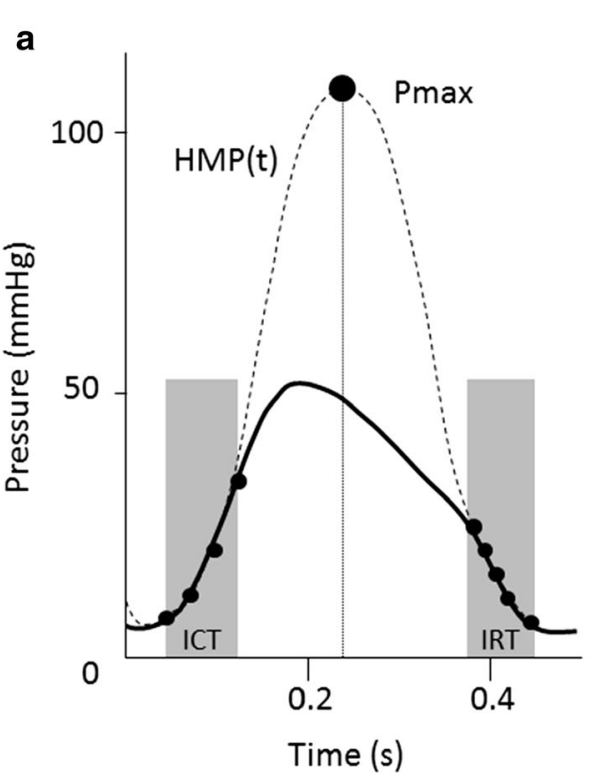

ventricle, such as the difficulty in determining Pes on pressure waveform, prolonged ejection after end-systole under the condition of low pulmonary arterial pressure, difficulty in determining the troughs of the extrapolated sine curve in short isovolumic contraction and relaxation phases [47], and lack of data of ejected volume after endsystole and regurgitant volume of the tricuspid valve.

\section{Right ventricle-pulmonary arterial coupling}

The ejected blood generates a pressure in the vascular tree, and this pressure behaves as ventricular afterload. In the pulmonary circulation, the right ventricular performance interacts closely with the hydraulic nature of the pulmonary artery [48-50]. As in the case of the left ventricle, the SV of the right ventricle is determined by the balance between ventricular contractility and afterload. The afterload can be evaluated as effective arterial elastance [51], which is defined as Pes divided by SV. The coupling efficiency is defined as Ees/Ea [52]. An animal study reported the normal value of Ees/Ea of the right ventricle in anesthetized $\operatorname{dogs}$ to be 1.64 [45]. The normal Ees/Ea of the right ventricle in humans has also been reported. While the estimated Ees/Ea is 1.9 in normal subjects, it decreases to 1.1 in patients with pulmonary hypertension with mean pulmonary arterial pressure of $57 \mathrm{mmHg}$ [46]. This fact may demonstrate the existence of a potential mismatch between right ventricular contractility and afterload in patients with pulmonary hypertension.

\section{Summary}

Although several hemodynamic parameters such as cardiac output, mean pulmonary pressure, and PVR are used to represent the hydraulic nature of the pulmonary circulation, simultaneous recording of pulmonary arterial pressure and flow waveforms is essential to obtain precise information of the hydraulic nature of the pulmonary circulation, such as pulmonary input impedance. Moreover, contractility of the right ventricle and coupling efficiency (Ees/Ea) can be measured by analyzing the pressure waveform of the right ventricle. Recording of pressure and flow waveform at high frequency without damping noise is necessary to achieve this analysis. Careful considerations of the physiological characteristics of the pulmonary circulation will optimize medical care for pulmonary hypertension.

\section{Physiological and anatomical factors affecting vein graft patency after coronary artery bypass grafting}

The coronary circulation is essential for normal functioning of the left and right ventricles. The stenosis or occlusion of coronary arteries leads to ischemic heart diseases and requires intravascular or surgical intervention. Coronary artery bypass grafting (CABG) is still more beneficial than percutaneous coronary intervention (PCI) in patients with triple-vessel coronary artery disease and in diabetic patients with multi-vessel disease [53, 54]. The clinical outcome after CABG is contingent on graft patency [55-57]. Although saphenous vein graft (SVG) is widely used, its patency is poorer compared with internal thoracic artery graft $[55,58]$. Other than technical errors, saphenous vein graft failure develops in three distinct phases; (1) thrombosis causing early graft failure, (2) intimal hyperplasia leading to stenosed lumen and graft failure by 1 year, and (3) atherosclerosis occurring subsequent to 
intimal hyperplasia $[59,60]$. Accurate intraoperative assessment of vein graft failure is important because technical errors can be corrected in the operative room. Also, predicting mid-term graft failure would be helpful for clinicians. In this section, we review how physiological and anatomical factors correlate with vein graft patency.

\section{Physiological factors}

\section{Wall shear stress}

Wall shear stress is known to play an important role in the process of intimal hyperplasia [61, 62]. The development of anastomotic intimal hyperplasia has been reported to connote a physiological adaptation of the vascular wall to lowered shear stresses prevailing in areas of flow separation [63]. Wall shear stress is also independently associated with intimal hyperplasia in saphenous vein [64]. When vein grafts adapt to the arterial system, i.e., high pressure system, vein grafts exposed to low shear stress respond primarily through enhanced intimal thickening, but highshear-stress grafts adapt through enhanced outward remodeling [65]. Therefore, an assessment of wall shear stress is essential for predicting graft patency.

Shear stress $(\tau)$ in Newtonian fluids can be calculated as below [66]:

$\tau(y)=\mu \cdot \frac{\partial u}{\partial y}$

where $\mu$ is the dynamic viscosity, $u$ is the flow velocity along the boundary, and $y$ is the distance from the boundary. Wall shear stress $\left(\tau_{\mathrm{w}}=\tau(0)\right.$, Fig. 8$)$ in blood vessels is simplified by the Hagen-Poiseuille's law [66]:

$\tau_{\mathrm{w}}=32 \cdot \mu \cdot \frac{Q}{\pi \cdot d^{3}}=8 \cdot \mu \cdot \frac{u_{\mathrm{ave}}}{d}$

where $Q$ is the mean volumetric flow rate, $u_{\text {ave }}$ is the average velocity, and $d$ is the vessel diameter. Therefore,

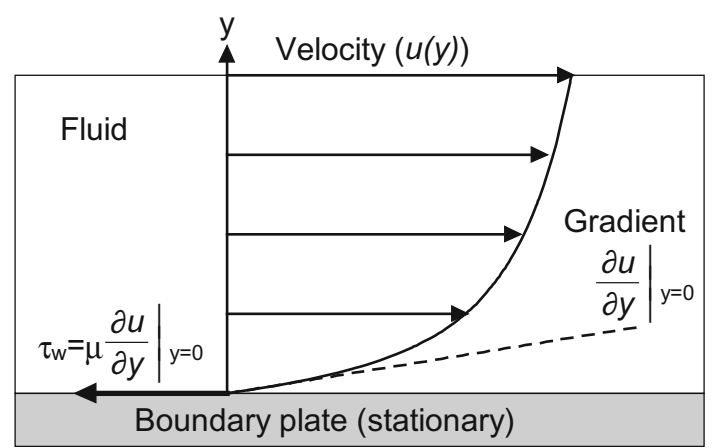

Fig. 8 Schematic representation of wall shear stress. Wall shear stress $\left(\tau_{\mathrm{w}}\right)$ is calculated as shear stress at $y=0 . \mu$ dynamic viscosity, $u(y)$ flow velocity along the boundary, $y$ the distance from the boundary the monitoring of graft volumetric flow or flow velocity with graft diameter, as an index of shear stress, can predict the volume of hyperplasia that may lead to graft failure by 1 year after CABG.

To evaluate shear stress more accurately, it is necessary to solve the Navier-Stokes equations for the velocity vector $(\boldsymbol{u})$ [67]. When the blood is assumed to be incompressible $(\rho=$ constant), the Navier-Stokes equations are described as below:

$\frac{\partial \boldsymbol{u}}{\partial t}+(\boldsymbol{u} \cdot \nabla) \boldsymbol{u}=-\frac{1}{\rho} \nabla p+v \nabla^{2} \boldsymbol{u}$,

$\nabla \cdot \boldsymbol{u}=0$

where $\rho$ is the blood density, $v$ is the kinematic viscosity $(v=\mu / \rho)$, and $p$ is the pressure. However, there has been a principal difficulty in the general solution of the NavierStokes equations. Recent development of computer technology enables us to solve these equations numerically even in a desktop computer using a commercial-based computational fluid dynamics (CFD) software [68]. Therefore, preoperative CFD simulation with computed tomographic images or magnetic resonance imaging images of coronary artery may accurately predict wall shear stress after operation. However, this does not consider technical errors, such as stenosed anastomosis. Therefore, intraoperative methods, such as a transit time flowmetry, may be more beneficial for surgeons.

\section{Graft flow}

Shear stress per se is not a parameter of clinical interest. Instead of shear stress, mean graft flow is usually measured and recorded in operative rooms. A transit time flowmetry that is easy and quick to operate is widely used all over the world for intraoperative assessment of graft blood flow. Previous studies revealed that lower graft flow was strongly associated with graft failure [69-72]. Technical errors such as bypass twist, kinking, and/or stenosed anastomosis can be detected easily during operation. However, the cut-off value for graft revision is difficult to determine. In the case of high-quality anastomosis, the volumetric flow depends largely on myocardial oxygen demand [73]. Furthermore, graft volumetric flow is affected by various factors including blood pressure, graft size, heart rate, myocardial volume, run-off, use of cardiopulmonary bypass, degree of hemodilution, degree of proximal stenosis in target vessel, and type of transit time flowmeter [74, 75]. With an inappropriate cut-off value, the result of transit time flowmetry sometimes suggests unnecessary revision $[72,76]$. Notwithstanding, volumetric flow was reported to predict mid-term graft failure [72, 77]. This may be because graft volumetric flow partially reflects wall shear 
stress as described above. Because wall shear stress is inversely proportional to the cube of vessel diameter, at the same volumetric flow, larger grafts have lower shear stress resulting in more hyperplasia $[61,62,78]$.

\section{Flow patterns}

Pulsatility index (PI), a common index of flow pattern, is also measured using transit time flowmetry. PI is derived from the difference between maximum $\left(Q_{\max }\right)$ and minimum flow $\left(Q_{\mathrm{min}}\right)$ divided by the mean flow $\left(Q_{\mathrm{m}}\right)$ [79].

$\mathrm{PI}=\frac{Q_{\max }-Q_{\min }}{Q_{\mathrm{m}}}$

High PI is associated with graft failure [69, 70, 80], indicating poor quality of the anastomosis with high anastomotic resistance. Although PI is recognized as an index of downstream resistance, its physiological meaning is still under dispute [81]. Mathematical models demonstrate that PI has no distinctive physiological meaning by itself [81] and there is a complex relationship between PI and multiple hemodynamic variables [82]. Therefore, further investigations are needed to clarify physiological meanings of PI.

Other indices of flow pattern, e.g., the percentage of diastolic flow or backward flow, are also reported to be associated with graft patency [69-71, 77]. However, physiological meanings of these indices are still under dispute as well as PI.

\section{Anatomical factors}

\section{Location of anastomosis}

The blood flow to the left coronary artery usually has a diastolic dominant flow pattern, while a bimodal flow pattern (systolic and diastolic) is observed in the right coronary artery [83]. Bypass grafts to the right coronary artery become occluded more frequently than those to the left coronary artery [78, 84]. Because temporal gradients in shear stress induce more intimal hyperplasia than spatial gradients [85], the bimodal flow pattern in the right coronary system likely contributes to more hyperplasia compared with the diastolic dominant flow pattern in the left coronary system.

\section{Degree of stenosis in target vessels}

Another important anatomical factor is the severity of proximal coronary stenosis in a target vessel. A CFD simulation demonstrated that, in the CABG model without proximal coronary stenosis, wall shear stress was markedly decreased in the vicinity of anastomosis and in the graft
[86]. Less severe proximal stenosis was clinically reported to be associated with diminished patency in SVGs and radial artery grafts, with a more prominent effect seen in radial arteries [87]. In addition to less shear stress, mild stenosis in proximal coronary artery is more likely to cause spasm of radial artery grafts $[88,89]$.

\section{Graft size and harvest techniques}

Because graft diameter is inversely proportional to wall shear stress, small vein graft is at lower risk of hyperplasia and graft failure $[78,90]$. Graft size depends on the harvest site and harvest technique. In a previous study, vein grafts harvested from the lower legs had better patency than those from the thigh [91]. In addition to choosing the appropriate harvest site, avoiding manual distension of vein grafts commonly practiced in conventional harvest techniques may improve graft patency. As for internal thoracic arteries, harvest method has no impact on graft flow or graft patency [73, 92]. In contrast, previous small studies showed that a no-touch harvesting technique for SVG provided excellent patency compared with conventional method [91, 93]. In the no-touch technique, the vein is harvested atraumatically along with a pedicle of fat, and is not manually distended. In addition to integrity of the vein wall and vaso vasorum, the size of grafts harvested by the non-touch method is more favorable compared with conventional method. An on-going multicenter clinical trial (SUPERIOR-SVG, clinicaltrials.gov: NCT01047449) [94] may show superiority of the no-touch harvesting technique.

\section{Other factors}

In clinical settings, secondary prevention therapy is also an important factor for graft patency. Recent studies revealed that dual antiplatelet therapy improved SVG patency or inhibited progression of native coronary disease after CABG [95-97]. These secondary prevention therapies may affect physiological factors through the modulation of endothelial functions.

\section{Summary}

Both physiological and anatomical factors predict vein graft patency. Lower graft flow, larger SVG, conventional harvest techniques, lower percentage of diastolic flow, higher percentage of backward flow, higher PI, and bypass to the right coronary artery are associated with worse graft patency during the early to mid-term period. In principle, accurate evaluation of wall shear stress is essential for 
Fig. 9 Schematic representation of two percutaneous LVADs. Impella ${ }^{\circledR}$ (a) pulls blood from the left ventricle into the ascending aorta. TandemHeart ${ }^{\mathrm{TM}}$

(b) pumps blood from the left atrium into one or both femoral arteries
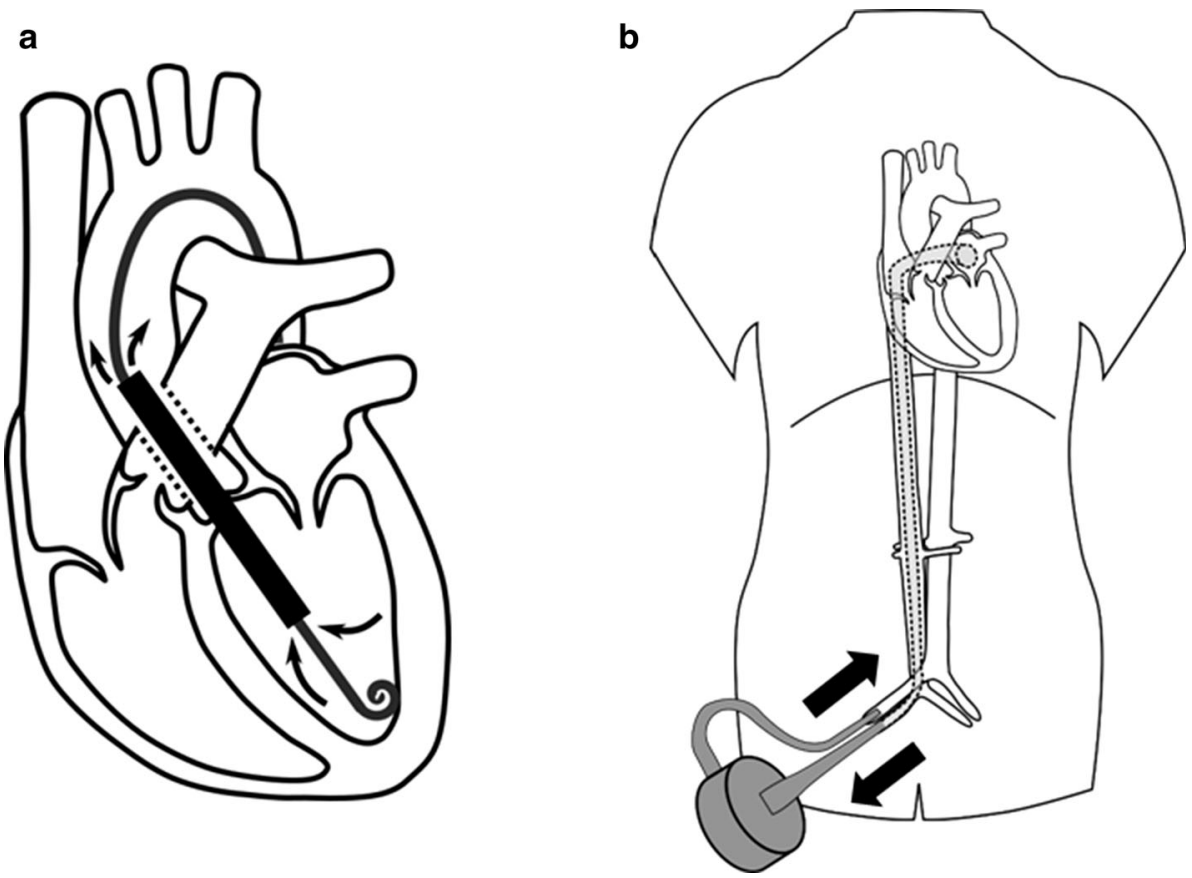

predicting mid-term graft failure. At least, graft diameter should be taken into consideration to improve the ability of intraoperative graft flow measurement.

\section{Mechanical unloading by left ventricular assist device for acute myocardial infarction}

Over the past few decades, significant progress has been made in left ventricular assist devices (LVADs). Especially, the progress in percutaneous LVADs has allowed their use in acute clinical settings such as temporary hemodynamic support in high-risk percutaneous coronary intervention and cardiogenic shock. LVAD decreases myocardial oxygen consumption $\left(\mathrm{MVO}_{2}\right)$ through mechanical unloading of the left ventricle. Since imbalance between oxygen supply and demand is the fundamental pathophysiology of myocardial infarction (MI), LVAD has been proposed as a novel strategy to minimize myocardial damage resulting from acute MI. In this section, we introduce a new therapeutic option of LVAD in the management of acute MI and discuss the physiological and mechanical impact of LVAD in terms of cardiac energetics.

\section{Development of left ventricular assist device}

In 1966, DeBakey [98] first implanted an LVAD for the treatment of postoperative cardiogenic shock. The LVAD improved cardiac function and was successfully removed after a week. LVADs were initially developed as a bridge to heart transplantation for patients with end-stage heart failure. However, they have been increasingly used as a destination therapy or bridge to recovery. The REMATCH trial demonstrated a significant survival advantage and improvement of quality of life in patients with end-stage heart failure treated with first-generation, implantable, pulsatile flow LVAD compared with optimal medical management [99]. Second-generation implantable LVADs that circulate blood in a continuous flow fashion using an internal rotor are smaller and have proven to be more durable than pulsatile first-generation LVADs. Clinical trial of HeartMate II, a second-generation implantable axial continuous flow pump, concluded that the device provides effective hemodynamic support for at least 18 months in patients awaiting transplantation, with improved functional status and quality of life [100]. Recently, temporary LVADs that can be placed percutaneously by cardiologists in the catheterization room are also available (Fig. 9) [101]. Percutaneous LVADs such as Impella ${ }^{\circledR}$ (Abiomed, Inc.; Danvers, MA, USA; Fig. 9a) and TandemHeart ${ }^{\mathrm{TM}}$ (Cardiac Assist, Inc.; Pittsburgh, PA, USA; Fig. 9b), have become essential tools in the treatment of cardiogenic shock [102] and high-risk percutaneous coronary intervention [103].

\section{Left ventricular assist device for the treatment of myocardial infarction}

Despite advances in early reperfusion therapy for patients with MI, $10 \%$ of patients die in the acute phase and about $30 \%$ develop heart failure in the long term [104]. Since the 
presence of residual myocardial damage leads to heart failure, there exists an unmet need to develop better cardioprotective strategies that improve the long-term outcome after MI. LVAD supports hemodynamics and unloads the left ventricle. In addition, the development of percutaneous LVADs allows application of the device to acute clinical setting.

The concept of left ventricular unloading using percutaneous LVAD to protect the ischemic left ventricle has been proposed and several animal and clinical studies have been conducted. Meyns and colleagues [105] reported that left ventricular unloading using Impella $^{\circledR}$ significantly reduced the infarct size in a sheep model of myocardial ischemia-reperfusion. Using an ischemia-reperfusion model, Kapur and colleagues [106] showed that left ventricular unloading by TandemHeart ${ }^{\mathrm{TM}}$ activated the RISK (reperfusion-injury salvage kinase) pathway that protects the myocardium from apoptosis, and significantly reduced infarct size despite longer ischemic exposure. In clinical trials, Engström and colleagues [107] reported the longterm effects of 3-day support with Impella $2.5^{\circledR}$ on left ventricular ejection fraction (LVEF). They concluded that Impella $2.5^{\circledR}$ significantly improved the recovery of LVEF. In addition, the USpella registry showed that initiation of LVAD support using Impella $2.5^{\circledR}$ prior to reperfusion was associated with more complete revascularization and improved survival in the setting of refractory cardiogenic shock complicating acute MI [108]. Based on these findings, Kapur and colleagues [106] proposed a novel concept

a

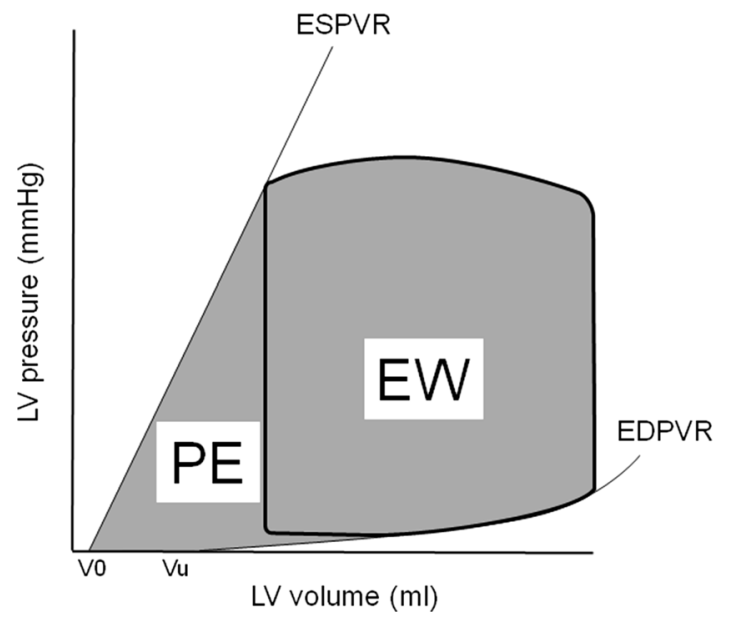

Fig. 10 a Pressure-volume area (PVA) indicated by the gray area is the sum of external work (EW) and potential energy (PE). PVA couples with myocardial oxygen consumption. b Theoretical analysis of the impact of left ventricular assist device (LVAD) on the pressure-volume (PV) loops. The loop in solid line represents the baseline PV loop. In partial LVAD support, LVAD decreases left ventricular end-diastolic volume and increases mean arterial pressure, of initial mechanical unloading of the ischemic left ventricle before coronary reperfusion, so-called "door to unloading", and emphasized its importance.

\section{Mechanical impact of left ventricular assist device on left ventricle}

Understanding the underlying pathophysiology is a prerequisite to optimal use of LVAD treatment in MI patients. Systolic PVA, a specific area circumscribed by the endsystolic and end-diastolic pressure-volume relation curves and the PV loop (Fig. 10a), represents the total mechanical work of each ventricular contraction. Since PVA tightly couples with myocardial oxygen consumption $\left(\mathrm{MVO}_{2}\right)$ [109], the impact of LVAD support on $\mathrm{MVO}_{2}$ can be revealed by examining PVA under the fixed heart rate (HR) condition. In this framework, LVAD decreases preload by withdrawing blood from the left ventricle and increases afterload by infusing blood into the aorta. Therefore, the impact of LVAD on PVA depends on the balance between the decreased preload and increased afterload. A theoretical analysis indicates that partial LVAD support, where the left ventricle remains ejecting, does not significantly decrease PVA [110]. In this setting, the impact on PVA is almost the same as that of extracorporeal membrane oxygenation [111, 112]. In contrast, total LVAD support, where the left ventricle no longer ejects, markedly reduces left ventricular pressure and volume, thereby significantly decreases PVA (Fig. 10b).

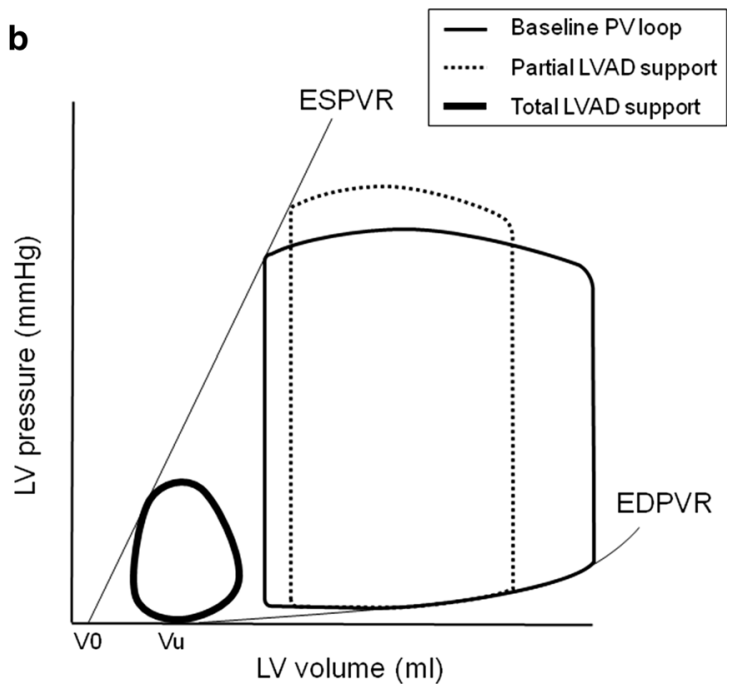

which in turn increases end-systolic volume (loop in dashed line). On the other hand, total LVAD support markedly lowers left ventricular pressure to below the arterial pressure, yielding an extremely small PVA (loop in bold line). EDPVR end-diastolic pressure volume relation, ESPVR end-systolic pressure volume relation, $V O$ the volume-axis intercept of ESPVR, $V u$ the volume-axis intercept of EDPVR 
Although some drugs such as $\beta$-blockers [113] and angiotensin-converting enzyme (ACE) inhibitors [114] have been known to reduce $\mathrm{MVO}_{2}$ and decrease the infarct size in MI or ischemia-reperfusion, these drugs do not stabilize the hemodynamics in an acute MI setting. LVAD is the only modality that markedly reduces PVA while stabilizing systemic hemodynamics. Thus, total LVAD support minimizes PVA and $\mathrm{MVO}_{2}$ of the left ventricle, and maximally reduces infarct size in MI patients without compromising systemic hemodynamics [110]. Considering these physiological and mechanical effects of LVAD on the left ventricle, LVAD has promising potential in MI treatment. In addition, heart rate is also the major component of $\mathrm{MVO}_{2}$ [115]. Therefore, the combination of bradycardic agent, e.g., If channel inhibitor, and LVAD will attribute to the further reduction of $\mathrm{MVO}_{2}$ and infarct size in MI. Appropriate left ventricular unloading will maximize the beneficial impact of LVAD in the clinical setting of acute MI.

\section{Conclusions}

We reviewed four selected topics of cardiovascular physiology. This review may leave several messages for clinicians. First, a noninvasive monitoring method of arterial stiffness may be useful in evaluating the left ventricular arterial coupling (Ees/Ea) in the clinical setting. Second, careful consideration of the unique physiological characteristics of pulmonary circulation may be essential in optimizing medical care for pulmonary hypertension. Third, accurate evaluation of wall shear stress may be helpful in predicting graft patency after CABG. Lastly, mechanical ventricular unloading using LVAD may be useful in improving the outcome of patients with acute MI.

Diagnostic and therapeutic methods for cardiovascular diseases will continue to be developed in the 21 st century. Insight into the physiological characteristics of the cardiovascular system is necessary for optimal uses of newly developed drugs and devices in patients with cardiovascular diseases. Clinical development of diagnostic and therapeutic modalities for cardiovascular diseases should be based on physiological insights of the cardiovascular system.

Acknowledgements Parts of this paper were presented at Symposium no. 59 in The Joint Meeting of the 120th Annual Meeting of The Japanese Association of Anatomists/the 92nd Annual Meeting of The Physiological Society of Japan, 2015.

\section{Compliance with ethical standards}

Funding This study has been supported in part by programs of the Research and development of supportive device technology for medicine using ICT and the Development of Advanced Measurement and Analysis Systems (SENTAN) from Japan Agency for Medical Research and Development, AMED.

Conflict of interest The authors declare that they have no conflicts of interest.

Ethical approval Human data was obtained from Fukui-ken Saiseikai Hospital Checkup Center and analyzed at University of Fukui Hospital. The study was approved by the human subject committees at University of Fukui Hospital (26-124). Consent was obtained using an opt-out approach.

\section{References}

1. Hayashi K, Shigemi K, Shishido T, Sugimachi M, Sunagawa K (2000) Single-beat estimation of ventricular end-systolic elastance-effective arterial elastance as an index of ventricular mechanoenergetic performance. Anesthesiology 92:1769-1776

2. Kubota T, Alexander J Jr, Itaya R, Todaka K, Sugimachi M, Sunagawa K, Nose Y, Takeshita A (1992) Dynamic effects of carotid sinus baroreflex on ventriculoarterial coupling studied in anesthetized dogs. Circ Res 70:1044-1053

3. Takeuchi M, Igarashi Y, Tomimoto S, Odake M, Hayashi T, Tsukamoto T, Hata K, Takaoka H, Fukazaki H (1991) Singlebeat estimation of the slope of the end-systolic pressure-volume relation in the human left ventricle. Circulation 83:202-212

4. Shih H, Hillel Z, Declerck C, Anagnostopoulos C, Kuroda M, Thys D (1997) An algorithm for real-time, continuous evaluation of left ventricular mechanics by single-beat estimation of arterial and ventricular elastance. J Clin Mont 13:157-170

5. Shishido T, Hayashi K, Shigemi K, Sato T, Sugimachi M, Sunagawa K (2000) Single-beat estimation of end-systolic elastance using bilinearly approximated time-varying elastance curve. Circulation 102:1983-1989

6. Sunagawa K, Maughan WL, Sagawa K (1985) Optimal arterial resistance for the maximal stroke work studied in isolated canine left ventricle. Circ Res 56:586-595

7. Takaku A, Obata Y, Hamada T, Mikami S, Kamisawa S, Sagami Y, Yasuda Y, Takakura K, Shigemi K (2015) Approximation of ventricular-arterial coupling (Ees/Ea) with mean arterial pressure $(\mathrm{Pm})$, diastolic arterial pressure $(\mathrm{Pd})$, pre-ejection period (PEP), and ejection time (ET), and clinical application. In: Technology in Anesthesia 2014. http://jsta.net/pdf/2014.pdf

8. Liu CP, Ting CT, Lawrence W, Maughan WL, Chang MS, Kass DA (1993) Diminished contractile response to increased heart rate in intact human left ventricular hypertrophy. Systolic versus diastolic determinants. Circulation 88:1893-1906

9. Georgakopoulos D, Mitzner WA, Chen CH, Byrne BJ, Millar HD, Hare JM, Kass DA (1998) In vivo murine left ventricular pressure-volume relations by miniaturized conductance micromanometry. Am J Physiol 274:H1416-H1422

10. Westerhof N, Elzinga G (1991) Normalized input impedance and arterial decay time over heart period are independent of animal size. Am J Physiol 261:R126-R133

11. O'Rourke MF, Taylor MG (1966) Vascular impedance of the femoral bed. Circ Res 18:129-139

12. Caro CG, McDonald DA (1961) The relation of pulsatile pressure and flow in the pulmonary vascular bed. J Physiol 157:426-453

13. Patel DJ, Defreitas FM, Fry DL (1963) Hydraulic input impedance to aorta and pulmonary artery in dogs. J Appl Physiol 18:134-140 
14. Bergel DH, Milnor WR (1965) Pulmonary vascular impedance in the dog. Circ Res 16:401-415

15. Dujardin JP, Stone DN (1981) Characteristic impedance of the proximal aorta determined in the time and frequency domain: a comparison. Med Biol Eng Comput 19:565-568

16. Mills CJ, Gabe IT, Gault JH, Mason DT, Ross J Jr, Braunwald E, Shillingford JP (1970) Pressure-flow relationships and vascular impedance in man. Cardiovasc Res 4:405-417

17. Milnor WR, Conti CR, Lewis KB, O'Rourke MF (1969) Pulmonary arterial pulse wave velocity and impedance in man. Circ Res 25:637-649

18. Murgo JP, Westerhof N (1984) Input impedance of the pulmonary arterial system in normal man. Effects of respiration and comparison to systemic impedance. Circ Res 54:666-673

19. Chen YT, Chen KS, Chen JS, Lin WW, Hu WH, Chang MK, Lee DY, Lee YS, Lin JR, Chiang BN (1990) Aortic and pulmonary input impedance in patients with cor pulmonale. Jpn Heart J 31:619-629

20. Slife DM, Latham RD, Sipkema P, Westerhof N (1990) Pulmonary arterial compliance at rest and exercise in normal humans. Am J Physiol 258:H1823-H1828

21. Laskey WK, Ferrari VA, Palevsky HI, Kussmaul WG (1993) Pulmonary artery hemodynamics in primary pulmonary hypertension. J Am Coll Cardiol 21:406-412

22. Noda T, Yaginuma T, O'Rourke MF, Hosoda S (2006) Effects of nifedipine on systemic and pulmonary vascular impedance in subjects undergoing cardiac catheterization. Hypertens Res 29:505-513

23. Yin FC, Guzman PA, Brin KP, Maughan WL, Brinker JA, Traill TA, Weiss JL, Weisfeldt ML (1983) Effect of nitroprusside on hydraulic vascular loads on the right and left ventricle of patients with heart failure. Circulation 67:1330-1339

24. Huez S, Brimioulle S, Naeije R, Vachiéry JL (2004) Feasibility of routine pulmonary arterial impedance measurements in pulmonary hypertension. Chest 125:2121-2128

25. Hunter KS, Lee PF, Lanning CJ, Ivy DD, Kirby KS, Claussen LR, Chan KC, Shandas R (2008) Pulmonary vascular input impedance is a combined measure of pulmonary vascular resistance and stiffness and predicts clinical outcomes better than pulmonary vascular resistance alone in pediatric patients with pulmonary hypertension. Am Heart J 155:166-174

26. Gleason WL, Braunwald E (1962) Studies on the first derivative of the ventricular pressure pulse in man. J Clin Invest 41:80-91

27. Stergiopulos N, Meister JJ, Westerhof N (1994) Simple and accurate way for estimating total and segmental arterial compliance: the pulse pressure method. Ann Biomed Eng 22:392-397

28. Mahapatra S, Nishimura RA, Sorajja P, Cha S, McGoon MD (2006) Relationship of pulmonary arterial capacitance and mortality in idiopathic pulmonary arterial hypertension. J Am Coll Cardiol 47:799-803

29. Lankhaar JW, Westerhof N, Faes TJ, Marques KM, Marcus JT, Postmus PE, Vonk-Noordegraaf A (2006) Quantification of right ventricular afterload in patients with and without pulmonary hypertension. Am J Physiol Heart Circ Physiol 291:H1731H1737

30. MacKenzie Ross RV, Toshner MR, Soon E, Naeije R, PepkeZaba J (2013) Decreased time constant of the pulmonary circulation in chronic thromboembolic pulmonary hypertension. Am J Physiol Heart Circ Physiol 305:H259-H264

31. Pagnamenta A, Vanderpool R, Brimioulle S, Naeije R (2013) Proximal pulmonary arterial obstruction decreases the time constant of the pulmonary circulation and increases right ventricular afterload. J Appl Physiol 114:1586-1592

32. West JB (1977) Regional differences in the lung. Academic Press, New York
33. West JB, Dollery CT, Naimark A (1964) Distribution of blood flow in isolated lung; relation to vascular and alveolar pressures. J Appl Physiol 19:713-724

34. Krishnan A, Linehan JH, Rickaby DA, Dawson CA (1986) Cat lung hemodynamics: comparison of experimental results and model predictions. J Appl Physiol 61:2023-2034

35. Naeije R (2003) Pulmonary vascular resistance. A meaningless variable? Intensive Care Med 29:526-529

36. Argiento P, Vanderpool RR, Mulè M, Russo MG, D'Alto M, Bossone E, Chesler NC, Naeije R (2012) Exercise stress echocardiography of the pulmonary circulation: limits of normal and sex differences. Chest 142:1158-1165

37. Voelkel NF, Quaife RA, Leinwand LA, Barst RJ, McGoon MD, Meldrum DR, Dupuis J, Long CS, Rubin LJ, Smart FW, Suzuki YJ, Gladwin M, Denholm EM, Gail DB; National Heart, Lung, and Blood Institute Working Group on Cellular and Molecular Mechanisms of Right Heart Failure (2006) Right ventricular function and failure: report of a National Heart, Lung, and Blood Institute working group on cellular and molecular mechanisms of right heart failure. Circulation 114:1883-1891

38. Sund T, Piene H (1983) Right ventricular mechanics: a comparison of models. Cardiovasc Res 17:320-330

39. Brown KA, Ditchey RV (1988) Human right ventricular endsystolic pressure-volume relation defined by maximal elastance. Circulation 78:81-91

40. Dell'Italia LJ, Walsh RA (1988) Application of a time varying elastance model to right ventricular performance in man. Cardiovasc Res 22:864-874

41. Suga H, Sagawa K (1974) Instantaneous pressure-volume relationships and their ratio in the excised, supported canine left ventricle. Circ Res 35:117-126

42. Baan J, van der Velde ET, de Bruin HG, Smeenk GJ, Koops J, van Dijk AD, Temmerman D, Senden J, Buis B (1984) Continuous measurement of left ventricular volume in animals and humans by conductance catheter. Circulation 70:812-823

43. Woodard JC, Bertram CD, Gow BS (1987) Right ventricular volumetry by catheter measurement of conductance. Pacing Clin Electrophysiol 10:862-870

44. Sunagawa K, Yamada A, Senda Y, Kikuchi Y, Nakamura M, Shibahara T, Nose Y (1980) Estimation of the hydromotive source pressure from ejecting beats of the left ventricle. IEEE Trans Biomed Eng 27:299-305

45. Brimioulle S, Wauthy P, Ewalenko P, Rondelet B, Vermeulen F, Kerbaul F, Naeije R (2003) Single-beat estimation of right ventricular end-systolic pressure-volume relationship. Am J Physiol Heart Circ Physiol 284:H1625-H1630

46. Kuehne T, Yilmaz S, Steendijk P, Moore P, Groenink M, Saaed M, Weber O, Higgins CB, Ewert P, Fleck E, Nagel E, SchulzeNeick I, Lange P (2004) Magnetic resonance imaging analysis of right ventricular pressure-volume loops: in vivo validation and clinical application in patients with pulmonary hypertension. Circulation 110:2010-2016

47. Bishop A, White P, Oldershaw P, Chaturvedi R, Brookes C, Redington A (1997) Clinical application of the conductance catheter technique in the adult human right ventricle. Int $\mathrm{J}$ Cardiol 58:211-221

48. Piene H, Sund T (1979) Flow and power output of right ventricle facing load with variable input impedance. Am J Physiol 237:H125-H130

49. Piene H (1980) Interaction between the right heart ventricle and its arterial load: a quantitative solution. Am J Physiol 238:H932-H937

50. Piene H, Sund T (1982) Does normal pulmonary impedance constitute the optimum load for the right ventricle? Am J Physiol 242:H154-H160 
51. Sunagawa K, Maughan WL, Burkhoff D, Sagawa K (1983) Left ventricular interaction with arterial load studied in isolated canine ventricle. Am J Physiol 245:H773-H780

52. Burkhoff D, Sagawa K (1986) Ventricular efficiency predicted by an analytical model. Am J Physiol 250:R1021-R1027

53. Mohr FW, Morice MC, Kappetein AP, Feldman TE, Ståhle E, Colombo A, Mack MJ, Holmes DR Jr, Morel MA, Van Dyck N, Houle VM, Dawkins KD, Serruys PW (2013) Coronary artery bypass graft surgery versus percutaneous coronary intervention in patients with three-vessel disease and left main coronary disease: 5-year follow-up of the randomised, clinical SYNTAX trial. Lancet 381:629-638

54. Farkouh ME, Domanski M, Sleeper LA, Siami FS, Dangas G, Mack M, Yang M, Cohen DJ, Rosenberg Y, Solomon SD, Desai AS, Gersh BJ, Magnuson EA, Lansky A, Boineau R, Weinberger J, Ramanathan K, Sousa JE, Rankin J, Bhargava B, Buse J, Hueb W, Smith CR, Muratov V, Bansilal S, King S 3rd, Bertrand M, Fuster V; FREEDOM Trial Investigators (2012) Strategies for multivessel revascularization in patients with diabetes. N Engl J Med 367:2375-2384

55. Alexander JH, Hafley G, Harrington RA, Peterson ED, Ferguson TB Jr, Lorenz TJ, Goyal A, Gibson M, Mack MJ, Gennevois D, Califf RM, Kouchoukos NT; PREVENT IV Investigators (2005) Efficacy and safety of edifoligide, an E2F transcription factor decoy, for prevention of vein graft failure following coronary artery bypass graft surgery: PREVENT IV: a randomized controlled trial. JAMA 294:2446-2454

56. Fitzgibbon GM, Kafka HP, Leach AJ, Keon WJ, Hooper GD, Burton JR (1996) Coronary bypass graft fate and patient outcome: angiographic follow-up of 5065 grafts related to survival and reoperation in 1388 patients during 25 years. J Am Coll Cardiol 28:616-626

57. Fabricius AM, Gerber W, Hanke M, Garbade J, Autschbach R, Mohr FW (2001) Early angiographic control of perioperative ischemia after coronary artery bypass grafting. Eur J Cardiothorac Surg 19:853-858

58. Shroyer AL, Grover FL, Hattler B, Collins JF, McDonald GO, Kozora E, Lucke JC, Baltz JH, Novitzky D; Veterans Affairs Randomized On/Off Bypass (ROOBY) Study Group (2009) Onpump versus off-pump coronary-artery bypass surgery. N Engl J Med 361:1827-1837

59. Wu J, Zhang C (2009) Neointimal hyperplasia, vein graft remodeling, and long-term patency. Am J Physiol Heart Circ Physiol 297:H1194-H1195

60. Lee S, Lee RT (2010) Mechanical stretch and intimal hyperplasia: the missing link? Arterioscler Thromb Vasc Biol 30:459-460

61. Malek AM, Alper SL, Izumo S (1999) Hemodynamic shear stress and its role in atherosclerosis. JAMA 282:2035-2042

62. Chiu JJ, Chien S (2011) Effects of disturbed flow on vascular endothelium: pathophysiological basis and clinical perspectives. Physiol Rev 91:327-387

63. Heise M, Krüger U, Rückert R, Pfitzman R, Neuhaus P, Settmacher U (2003) Correlation of intimal hyperplasia development and shear stress distribution at the distal end-sideanastomosis, in vitro study using particle image velocimetry. Eur J Vasc Endovasc Surg 26:357-366

64. Gusic RJ, Myung R, Petko M, Gaynor JW, Gooch KJ (2005) Shear stress and pressure modulate saphenous vein remodeling ex vivo. J Biomech 38:1760-1769

65. Jiang Z, Wu L, Miller BL, Goldman DR, Fernandez CM, Abouhamze ZS, Ozaki CK, Berceli SA (2004) A novel vein graft model: adaptation to differential flow environments. Am J Physiol Heart Circ Physiol 286:H240-H245

66. Papaioannou TG, Stefanadis C (2005) Vascular wall shear stress: basic principles and methods. Hellenic J Cardiol 46:9-15
67. Sankaranarayanan M, Chua LP, Ghista DN, Tan YS (2005) Computational model of blood flow in the aorto-coronary bypass graft. Biomed Eng Online 4:14

68. Dur O, Coskun ST, Coskun KO, Frakes D, Kara LB, Pekkan K (2011) Computer-aided patient-specific coronary artery graft design improvements using CFD coupled shape optimizer. Cardiovasc Eng Technol 2:35-47

69. Di Giammarco G, Pano M, Cirmeni S, Pelini P, Vitolla G, Di Mauro M (2006) Predictive value of intraoperative transit-time flow measurement for short-term graft patency in coronary surgery. J Thorac Cardiovasc Surg 132:468-474

70. Kim KB, Kang CH, Lim C (2005) Prediction of graft flow impairment by intraoperative transit time flow measurement in off-pump coronary artery bypass using arterial grafts. Ann Thorac Surg 80:594-598

71. Tokuda Y, Song MH, Ueda Y, Usui A, Akita T (2007) Predicting early coronary artery bypass graft failure by intraoperative transit time flow measurement. Ann Thorac Surg 84:1928-1933

72. Une D, Deb S, Chikazawa G, Kommaraju K, Tsuneyoshi H, Karkhanis R, Singh S, Vincent J, Tsubota H, Sever J, Moussa F, Cohen G, Christakis GT, Fremes SE (2013) Cut-off values for transit time flowmetry: are the revision criteria appropriate? J Card Surg 28:3-7

73. Une D, Shimizu S, Kamiya A, Kawada T, Shishido T, Sugimachi M (2010) Both skeletonized and pedicled internal thoracic arteries supply adequate graft flow after coronary artery bypass grafting even during intense sympathoexcitation. J Physiol Sci 60:407-413

74. Leacche M, Balaguer JM, Byrne JG (2009) Intraoperative grafts assessment. Semin Thorac Cardiovasc Surg 21:207-212

75. Nordgaard HB, Vitale N, Astudillo R, Renzulli A, Romundstad P, Haaverstad R (2010) Pulsatility index variations using two different transit-time flowmeters in coronary artery bypass surgery. Eur J Cardiothorac Surg 37:1063-1067

76. Jokinen JJ, Werkkala K, Vainikka T, Peräkylä T, Simpanen J, Ihlberg L (2011) Clinical value of intra-operative transit-time flow measurement for coronary artery bypass grafting: a prospective angiography-controlled study. Eur J Cardiothorac Surg 39:918-923

77. Tokuda Y, Song MH, Oshima H, Usui A, Ueda Y (2008) Predicting midterm coronary artery bypass graft failure by intraoperative transit time flow measurement. Ann Thorac Surg 86:532-536

78. Une D, Kulik A, Voisine P, Le May M, Ruel M (2013) Correlates of saphenous vein graft hyperplasia and occlusion 1 year after coronary artery bypass grafting: analysis from the CASCADE randomized trial. Circulation 128:S213-S218

79. Balacumaraswami L, Taggart DP (2007) Intraoperative imaging techniques to assess coronary artery bypass graft patency. Ann Thorac Surg 83:2251-2257

80. Kieser TM, Rose S, Kowalewski R, Belenkie I (2010) Transittime flow predicts outcomes in coronary artery bypass graft patients: a series of 1000 consecutive arterial grafts. Eur J Cardiothorac Surg 38:155-162

81. Michel E, Zernikow B (1998) Gosling's Doppler pulsatility index revisited. Ultrasound Med Biol 24:597-599

82. de Riva N, Budohoski KP, Smielewski P, Kasprowicz M, Zweifel C, Steiner LA, Reinhard M, Fábregas N, Pickard JD, Czosnyka M (2012) Transcranial Doppler pulsatility index: what it is and what it isn't. Neurocrit Care 17:58-66

83. Ofili EO, Labovitz AJ, Kern MJ (1993) Coronary flow velocity dynamics in normal and diseased arteries. Am J Cardiol 71:3D9D

84. Cataldo G, Braga M, Pirotta N, Lavezzari M, Rovelli F, Marubini E (1993) Factors influencing 1-year patency of 
coronary artery saphenous vein grafts. Studio Indobufene nel Bypass Aortocoronarico (SINBA). Circulation 88:II93-II98

85. White CR, Haidekker M, Bao X, Frangos JA (2001) Temporal gradients in shear, but not spatial gradients, stimulate endothelial cell proliferation. Circulation 103:2508-2513

86. Nordgaard H, Swillens A, Nordhaug D, Kirkeby-Garstad I, Van Loo D, Vitale N, Segers P, Haaverstad R, Lovstakken L (2010) Impact of competitive flow on wall shear stress in coronary surgery: computational fluid dynamics of a LIMA-LAD model. Cardiovasc Res 88:512-519

87. Deb S, Cohen EA, Singh SK, Une D, Laupacis A, Fremes SE; RAPS Investigators (2012) Radial artery and saphenous vein patency more than 5 years after coronary artery bypass surgery: results from RAPS (Radial Artery Patency Study). J Am Coll Cardiol 60:28-35

88. Desai ND, Cohen EA, Naylor CD, Fremes SE; Radial Artery Patency Study Investigators (2004) A randomized comparison of radial-artery and saphenous-vein coronary bypass grafts. N Engl J Med 351:2302-2309

89. Desai ND, Naylor CD, Kiss A, Cohen EA, Feder-Elituv R, Miwa S, Radhakrishnan S, Dubbin J, Schwartz L, Fremes SE; Radial Artery Patency Study Investigators (2007) Impact of patient and target-vessel characteristics on arterial and venous bypass graft patency: Insight from a randomized trial. Circulation 115:684-691

90. Shah PJ, Gordon I, Fuller J, Seevanayagam S, Rosalion A, Tatoulis J, Raman JS, Buxton BF (2003) Factors affecting saphenous vein graft patency: clinical and angiographic study in 1402 symptomatic patients operated on between 1977 and 1999. J Thorac Cardiovasc Surg 126:1972-1977

91. Souza DS, Dashwood MR, Tsui JC, Filbey D, Bodin L, Johansson B, Borowiec J (2002) Improved patency in vein grafts harvested with surrounding tissue: results of a randomized study using three harvesting techniques. Ann Thorac Surg 73:1189-1195

92. Calafiore AM, Vitolla G, Iaco AL, Fino C, Di Giammarco G, Marchesani F, Teodori G, D'Addario G, Mazzei V (1999) Bilateral internal mammary artery grafting: midterm results of pedicled versus skeletonized conduits. Ann Thorac Surg 67:1637-1642

93. Souza DS, Johansson B, Bojö L, Karlsson R, Geijer H, Filbey D, Bodin L, Arbeus M, Dashwood MR (2006) Harvesting the saphenous vein with surrounding tissue for CABG provides long-term graft patency comparable to the left internal thoracic artery: results of a randomized longitudinal trial. J Thorac Cardiovasc Surg 132:373-378

94. Unique identifier: NCT01047449. http://www.clinicaltrials.gov

95. Deo SV, Dunlay SM, Shah IK, Altarabsheh SE, Erwin PJ, Boilson BA, Park SJ, Joyce LD (2013) Dual anti-platelet therapy after coronary artery bypass grafting: is there any benefit? A systematic review and meta-analysis. J Card Surg 28:109-116

96. Nocerino AG, Achenbach S, Taylor AJ (2013) Meta-analysis of effect of single versus dual antiplatelet therapy on early patency of bypass conduits after coronary artery bypass grafting. Am J Cardiol 112:1576-1579

97. Une D, Al-Atassi T, Kulik A, Voisine P, Le May M, Ruel M (2014) Impact of clopidogrel plus aspirin versus aspirin alone on the progression of native coronary artery disease after bypass surgery: analysis from the clopidogrel after surgery for coronary artery disease (CASCADE) randomized trial. Circulation 130:S12-S18

98. DeBakey ME (1971) Left ventricular bypass pump for cardiac assistance. Clinical experience. Am J Cardiol 27:3-11

99. Rose EA, Gelijns AC, Moskowitz AJ, Heitjan DF, Stevenson LW, Dembitsky W, Long JW, Ascheim DD, Tierney AR, Levitan RG, Watson JT, Meier P, Ronan NS, Shapiro PA, Lazar RM, Miller LW, Gupta L, Frazier OH, Desvigne-Nickens P, Oz
MC, Poirier VL; Randomized Evaluation of Mechanical Assistance for the Treatment of Congestive Heart Failure (REMATCH) Study Group (2001) Long-term use of a left ventricular assist device for end-stage heart failure. N Engl J Med 345:1435-1443

100. Pagani FD, Miller LW, Russell SD, Aaronson KD, John R, Boyle AJ, Conte JV, Bogaev RC, MacGillivray TE, Naka Y, Mancini D, Massey HT, Chen L, Klodell CT, Aranda JM, Moazami N, Ewald GA, Farrar DJ, Frazier OH; HeartMate II Investigators (2009) Extended mechanical circulatory support with a continuous-flow rotary left ventricular assist device. J Am Coll Cardiol 54:312-321

101. Desai NR, Bhatt DL (2009) Evaluating percutaneous support for cardiogenic shock: data shock and sticker shock. Eur Heart J 30:2073-2075

102. Cheng JM, den Uil CA, Hoeks SE, van der Ent M, Jewbali LS, van Domburg RT, Serruys PW (2009) Percutaneous left ventricular assist devices versus intra-aortic balloon pump counterpulsation for treatment of cardiogenic shock: a meta-analysis of controlled trials. Eur Heart J 30:2102-2108

103. Seyfarth M, Sibbing D, Bauer I, Fröhlich G, Bott-Flügel L, Byrne R, Dirschinger J, Kastrati A, Schömig A (2008) A randomized clinical trial to evaluate the safety and efficacy of a percutaneous left ventricular assist device versus intra-aortic balloon pumping for treatment of cardiogenic shock caused by myocardial infarction. J Am Coll Cardiol 52:1584-1588

104. Velagaleti RS, Pencina MJ, Murabito JM, Wang TJ, Parikh NI, D’Agostino RB, Levy D, Kannel WB, Vasan RS (2008) Longterm trends in the incidence of heart failure after myocardial infarction. Circulation 118:2057-2062

105. Meyns B, Stolinski J, Leunens V, Verbeken E, Flameng W (2003) Left ventricular support by catheter-mounted axial flow pump reduces infarct size. J Am Coll Cardiol 41:1087-1095

106. Kapur NK, Paruchuri V, Urbano-Morales JA, Mackey EE, Daly GH, Qiao X, Pandian N, Perides G, Karas RH (2013) Mechanically unloading the left ventricle before coronary reperfusion reduces left ventricular wall stress and myocardial infarct size. Circulation 128:328-336

107. Engström AE, Sjauw KD, Baan J, Remmelink M, Claessen BE, Kikkert WJ, Hoebers LP, Vis MM, Koch KT, Meuwissen MM, Tijssen JG, De Winter RJ, Piek JJ, Henriques JP (2011) Longterm safety and sustained left ventricular recovery: long-term results of percutaneous left ventricular support with Impella LP2.5 in ST-elevation myocardial infarction. EuroIntervention 6:860-865

108. O'Neill WW, Schreiber T, Wohns DH, Rihal C, Naidu SS, Civitello AB, Dixon SR, Massaro JM, Maini B, Ohman EM (2014) The current use of Impella 2.5 in acute myocardial infarction complicated by cardiogenic shock: results from the USpella Registry. J Interv Cardiol 27:1-11

109. Suga H, Hisano R, Goto Y, Yamada O, Igarashi Y (1983) Effect of positive inotropic agents on the relation between oxygen consumption and systolic pressure volume area in canine left ventricle. Circ Res 53:306-318

110. Saku K, Kakino T, Arimura T, Sakamoto T, Nishikawa T, Sakamoto K, Ikeda M, Kishi T, Ide T, Sunagawa K (2016) Total mechanical unloading minimizes metabolic demand of left ventricle and dramatically reduces infarct size in myocardial infarction. PLoS One 11:e0152911

111. Kawashima D, Gojo S, Nishimura T, Itoda Y, Kitahori K, Motomura N, Morota T, Murakami A, Takamoto S, Kyo S, Ono M (2011) Left ventricular mechanical support with Impella provides more ventricular unloading in heart failure than extracorporeal membrane oxygenation. ASAIO J 57:169-176

112. Sakamoto K, Saku K, Kishi T, Kakino T, Tanaka A, Sakamoto T, Ide T, Sunagawa K (2015) Prediction of the impact of 
venoarterial extracorporeal membrane oxygenation on hemodynamics. Am J Physiol Heart Circ Physiol 308:H921-H930

113. Bates ER (2007) Role of intravenous beta-blockers in the treatment of ST-elevation myocardial infarction: of mice (dogs, pigs) and men. Circulation 115:2904-2906

114. ACE Inhibitor Myocardial Infarction Collaborative Group (1998) Indications for ACE inhibitors in the early treatment of acute myocardial infarction: systematic overview of individual data from 100,000 patients in randomized trials. Circulation 97:2202-2212

115. Tanaka N, Nozawa T, Yasumura Y, Futaki S, Hiramori K, Suga H (1990) Heart-rate-proportional oxygen consumption for constant cardiac work in dog heart. Jpn J Physiol 40:503-521 